\title{
Remission of severe aphthous stomatitis of celiac disease with etanercept
}

\author{
Adey Hasan ${ }^{1,2}$, Hiren Patel ${ }^{1,2}$, Hana Saleh ${ }^{1,2}$, George Youngberg ${ }^{4}$, John Litchfield ${ }^{1}$ and Guha Krishnaswamy ${ }^{1,2,3,5^{*}}$
}

\begin{abstract}
Celiac disease is a common autoimmune disease triggered by gluten-containing foods (wheat, barley and rye) in genetically predisposed individuals. We present a patient with celiac disease complicated by severe aphthous stomatitis resulting in impairing swallowing, chewing and speaking. This led to weight loss, psychosocial problems as well as inability to perform her work. A variety of topical and systemic medications used resulted in either no improvement or only partial alleviation of the patient's symptoms. After informed consent, etanercept was initiated and resulted in complete remission of aphthous stomatitis, decrease in arthralgia and fatigue and considerable improvement in her quality of life. The use of newer biological agents for selected and severe manifestations of celiac disease may lead to improved morbidity in these patients, but more studies are needed to determine long-term efficacy as well as safety of these drugs in the mucosal and/or systemic complications of this disease.
\end{abstract}

Keywords: Celiac disease, Gluten-sensitivity, Aphthous stomatitis, Etanercept, Tumor necrosis factor

\section{Introduction}

Celiac disease (CD) is a common autoimmune disease. The prevalence of $\mathrm{CD}$ is approximately $0.5 \%$ to $1 \%$ among people living in the United States [1] and 1:100 to 1:300 worldwide [2]. It is more common in Caucasians and affects both children and adults, with a female predominance [1]. CD- otherwise known as Gluten-sensitive enteropathy- is triggered by gluten-containing foods (wheat, barley and rye) in genetically predisposed individuals and can also be associated with other immunological diseases such as diabetes mellitus type 1 and IgA deficiency, suggesting immune dysregulation. Although patients are often asymptomatic, $\mathrm{CD}$ can manifest with cutaneous, mucosal, systemic or autoimmune features [3,4]. A variety of oral lesions such as atrophic glossitis and aphthous ulcers are quite common in patients with $\mathrm{CD}$ with A prevalence ranging from $3 \%$ to $61 \%$ in several studies. Aphthous stomatitis can be quite severe in $\mathrm{CD}$, at time interfering with chewing, swallowing, speaking, and leading to impaired quality of life. This can result in complications

\footnotetext{
*Correspondence: krishnas@etsu.edu

'The Department of Internal Medicine, East Tennessee State University, Johnson City, TN, USA

${ }^{2}$ Division of Allergy, Asthma and Immunology, East Tennessee State University, PO Box 70622, Johnson City, TN, USA

Full list of author information is available at the end of the article
}

such as weight loss, nutrition deficiencies, depression and psychosocial withdrawal.

We present a patient with severe aphthous stomatitis complicating $\mathrm{CD}$ who responded partially to immune suppression, but dramatically to the inhibitor of tumor necrosis factor alpha (TNF $\alpha$ ) - Etanercept. This report suggests a role for cytokines such as TNFo in CD, and also provides a potential treatment strategy for selected mucosal complications associated with the disease.

\section{Case report}

A 32 year old Caucasian female with a history of endometriosis and fibrocystic breast disease presented with severe ulcers of the mouth extending into the posterior oropharynx. The presence of the ulcers was associated with severe pain with difficulty eating, chewing or swallowing, and interfered with her speech and quality of life. The lesions appeared initially as blisters and were followed by ulceration. These appeared in clusters over weeks or months leading to severe disability. Periodically, the patient would develop conjunctival injection, arthralgias and severe fatigue associated with the ulcers. A thorough ophthalmological evaluation was negative for glaucoma, cataracts, uveitis or scleritis.

The past medical history included allergic rhinitis complicated by recurrent sinusitis. She also complained

\section{Biomed Central}


of tingling, pain and erythema with blanching of her fingers, consistent with Raynaud's phenomenon. The patient's medications included fexofenadine, montelukast sodium, intranasal steroids, tryptan for migraine and sertraline. A recent gynecological examination was unremarkable. Her family history was significant for a first cousin with systemic lupus erythematosus (SLE). Physical examination revealed multiple large aphthous ulcers with involvement of the buccal mucosae, tongue and palate (Figure $1 \mathrm{~A}$ and $\mathrm{B}$ ). A few lymph nodes in the upper neck were slightly enlarged. Raynaud's phenomenon and livedoid changes were seen in the upper extremities.

A thorough evaluation demonstrated normal liver function tests, low levels of Vitamin D, ferritin $(19 \mathrm{ng} / \mathrm{ml})$ and thiamine $(52 \mathrm{ng} / \mathrm{ml})$ with normal levels of B12 and red blood cell folate (Table 1). Tests for autoantibodies and anti-cardiolipin antibodies were negative. Evaluation for CD demonstrated significantly elevated levels of endomysial and tissue transglutaminase (TTG) antibodies (Table 2). Biopsies of the esophagus demonstrated typical reflux changes, while biopsies of the ileum showed villous blunting, mononuclear and $\mathrm{T}$ cell infiltration of the lamina propria and epithelial loss (Figure $1 \mathrm{C}$ and D), confirming the diagnosis of CD. Genetic evaluation and HLA-DQ typing demonstrated the presence of celiac disease permissive alleles DQ alpha 1 0103, 0501 and DQ beta 1 0201, 0603, further clinching the diagnosis. These results are summarized in (Table 2), colonoscopy and biopsy were negative for Inflammatory bowel disease. Biopsy of oral lesion did not reveal vasculitis or Behcets syndrome.

Tetracycline swish and swallow as well as topical lidocaine for the ulcers were initially prescribed. Replacement with Vitamin D, thiamine and iron were initiated and the patient was instructed to follow a strict gluten-free diet. Reflux symptoms were also treated with a proton pump inhibitor. The oral ulcers showed no response to tetracycline and lidocaine but a partial response to systemic glucocorticoids was seen, with relapse of symptoms soon after discontinuation. A repeat endoscopy showed normalization of the villous architecture in response to treatment; however, the aphthous ulcers persisted unabated.

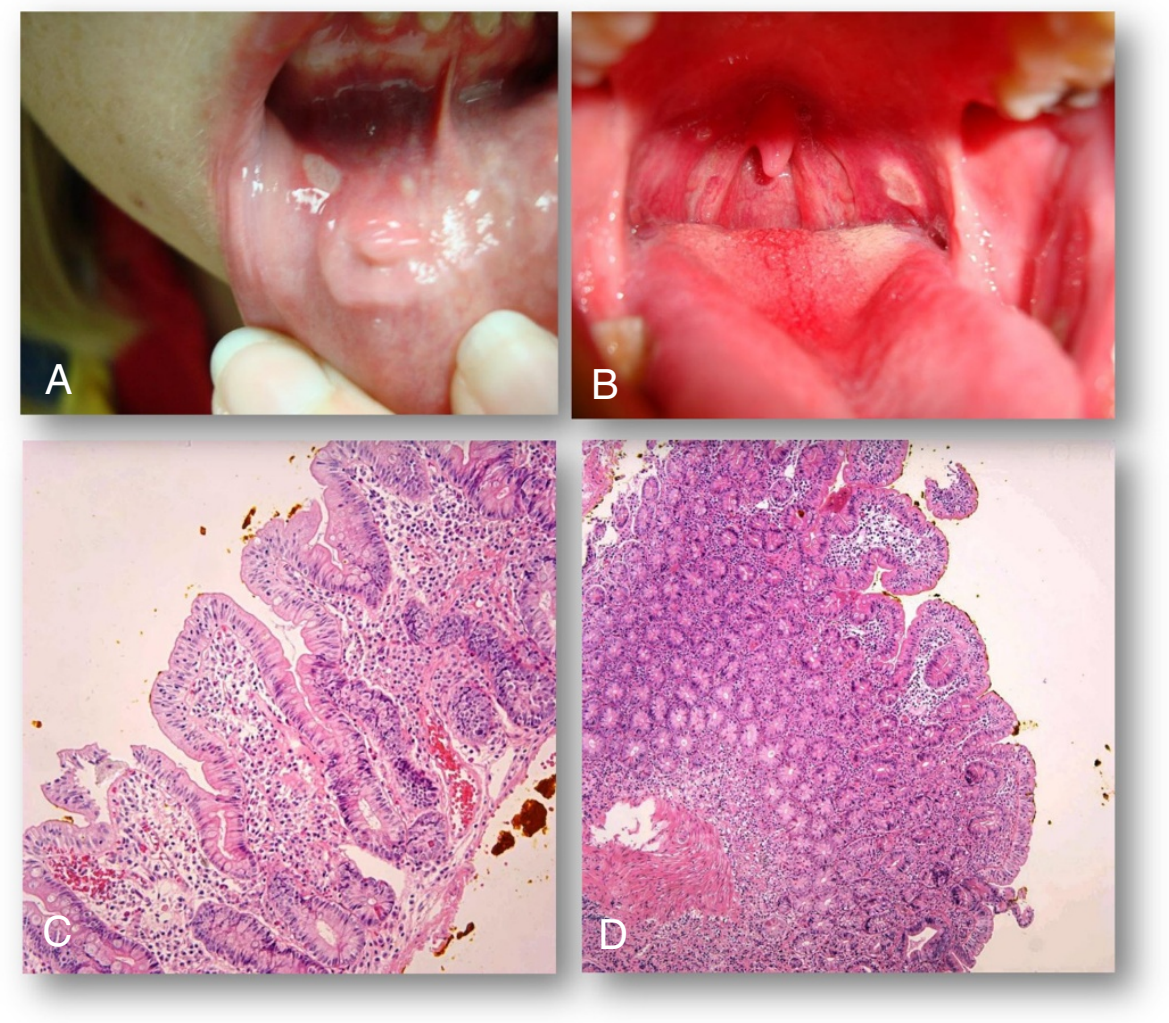

Figure 1 Images of physical examination findings and biopsy results. A-D: Gross examination of the oral mucosa demonstrated multiple aphthous ulcers and erythema. (A) A large, painful white ulcer with surrounding erythema located on the soft palate is present. (B) Demonstrates large, shaggy, inflamed ulceration of the lower lip. Granulation tissue, scarring and ulceration were also observed on biopsy of the lower labial mucosa. (C \& D) lleal biopsy revealed villous blunting, crypt elongation, increased inflammation in the lamina propria, and increased intraepithelial lymphocytes (C-low power, D-high power). 
Table 1 Other laboratory test results on patient

\begin{tabular}{|c|c|c|c|}
\hline Name & Result & Normal value & Comments \\
\hline Anti-nuclear Ab (U/ml) & 46 & $0-100$ & Normal \\
\hline Anti-SSA Ab (U/ml) & 44 & $0-100$ & Normal \\
\hline Anti-SSB Ab (U/ml) & 7 & $0-100$ & Normal \\
\hline Cardiolipin IgG (GPL) & 7 & $<15$ & Normal \\
\hline Cardiolipin IgM (MPL) & 8 & $<12$ & Normal \\
\hline Cardiolipin Ab IgA (APL) & 2 & $<12$ & Normal \\
\hline Rheumatoid factor (IU/ml) & $<5$ & $0-10$ & Normal \\
\hline Anti-CCP Ab (Units) & 3 & $<20$ & Normal \\
\hline C3 complement (mg/dL) & 119 & $89-187$ & Normal \\
\hline C4 complement (mg/dL) & 46.3 & $16.5-38.0$ & Increased-acute phase \\
\hline $\lg A(\mathrm{mg} / \mathrm{dL})$ & 82 & $66-436$ & Normal \\
\hline Vitamin B1 (nmol/L) & 52 & $70-180$ & Low \\
\hline Ferritin (ng/mL) & 19 & $6-159$ & Fe deficiency \\
\hline Vitamin B12 (pg/mL) & 425 & 193-982 & Normal \\
\hline RBC folate $(\mathrm{ng} / \mathrm{mL})$ & 486 & 280-903 & Normal \\
\hline TSH (IU/ml) & 2.28 & $0.4-4.0$ & Normal \\
\hline WBC (K/microL) & 4.4 & $4.8-10.8$ & Mild leukopenia \\
\hline $\mathrm{Hgb}(\mathrm{g} / \mathrm{dL})$ & 11.4 & $12.0-16.0$ & Decreased; anemia \\
\hline
\end{tabular}

The patient continued to require more prednisone and narcotics for pain. A lip biopsy was performed and demonstrated mucositis and granulation tissue. Fungal stains and PCR for herpes simplex virus were negative.

The patient was started on and failed hydroxychloroquine, sucralfate, cyclosporine, azathioprine and colchicine. After informed consent and insurance approval, the patient was started on etanercept at a dose of $25 \mathrm{mg}$ biweekly administered subcutaneously, after an initial negative tuberculin skin test. After adequate instruction, the patient was able to comfortably self-administer the medication. Pulmicort $^{\oplus}$ Respules were prescribed for minor flares. After Etanercept was initiated, the patient had complete remission of the oral ulcers. She has also had dramatic improvements in the inflammatory symptoms including conjunctival inflammation, polyarthralgia and fatigue.

\section{Discussion}

\section{Celiac disease and its manifestation}

Celiac disease is a chronic inflammatory, autoimmune disorder of the small intestine with local and systemic manifestations (Figure 2) [5-7]. The latter include mucosal disease (dental/enamel hypoplasia, malabsorption syndrome, aphthous stomatitis), dermatitis herpetiformis, osteopenia/ osteoporosis, nutritional issues such as short stature and malnutrition with hypovitaminoses, infertility and delayed puberty, seizures and/or ataxia, depression and autoimmune endocrinopathy [5-7].

Table 2 Diagnostic immunological test results

\begin{tabular}{llll}
\hline Test & Result & Normal value & Comments \\
\hline Gliadin IgG Ab (Units) & 69 & $<19$ negative; 19-31 weak positive; $>31$ positive & Positive suggestive of celiac disease \\
Gliadin IgA Ab (Units) & 11 & $<19$ & Normal \\
Transglutaminase IgA Ab (Units) & 72 & $0-19$ & Increased suggestive of celiac disease \\
Tissue transglutaminase IgG antibody (Units) & 5 & $<20$ & Normal \\
Endomysial antibody titer & $1: 40$ & $<1: 10$ & Increased suggestive if celiac disease \\
DQ alpha $\mathbf{1}$ (MHR) & 0103,0501 & Positive; indicating genetic \\
& & predisposition \\
DQ beta $\mathbf{1}$ (MHR) & 0201,0603 & Positive; indicates genetic \\
& & predisposition \\
\hline
\end{tabular}




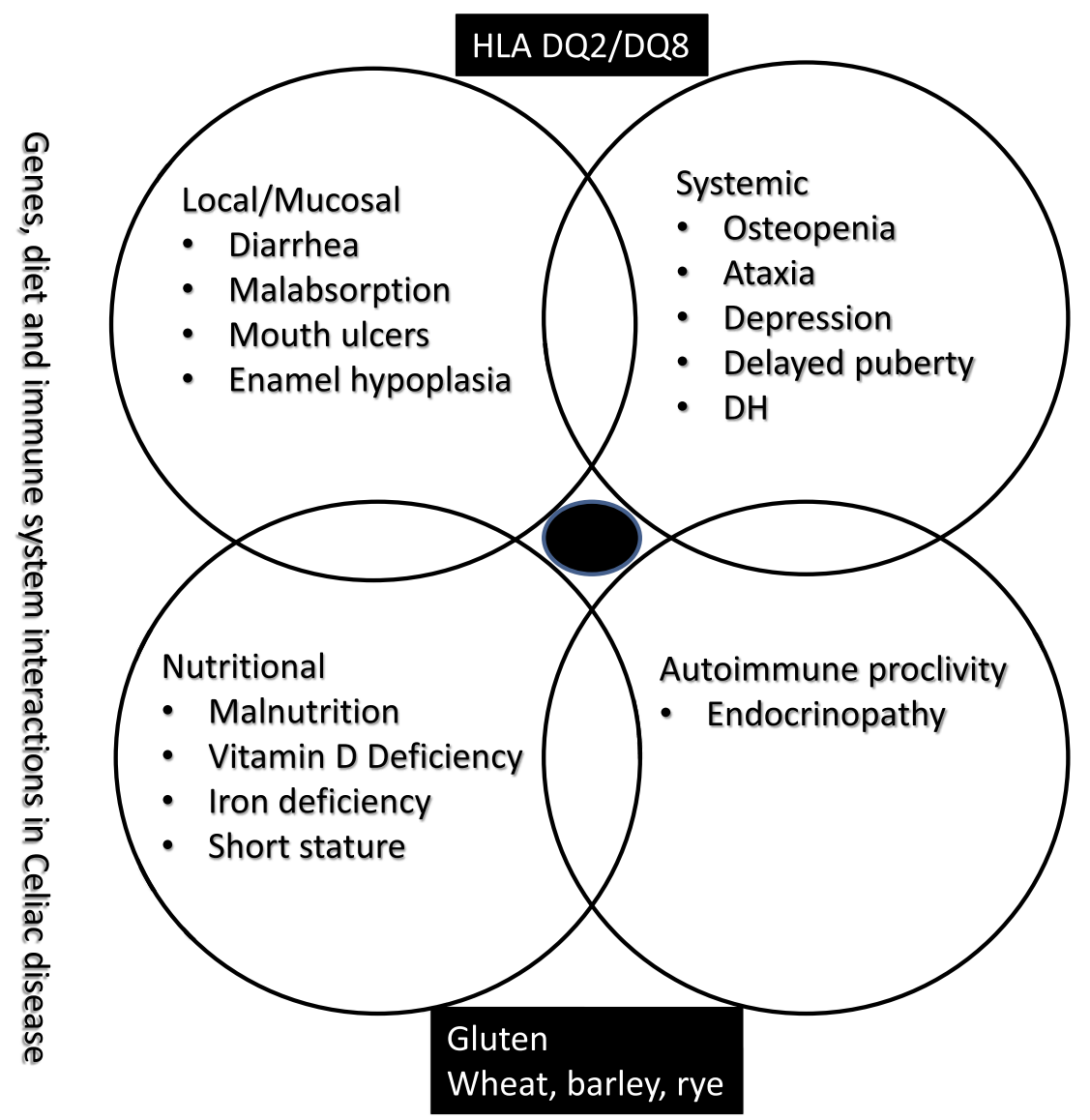

\section{Wheat/Rye/Barley \\ - Gluten peptides}

\section{HLA DQ2/8 etc}

Antigen presenting cells

T Cell activation

IL-18

\section{Cytokines \\ IFN $\gamma$ \\ TNF- $\alpha$ \\ $\mathrm{L}-21$ etc \\ IL-15/IL-17}

Anti-TNF therapy

Etanercept?

\section{Celiac disease}

Disease manifestations

Figure 3 Immunopathogenesis of celiac disease and possible point of action of etanercept. 
Pathogenesis of CD is an interaction between immunological factors and environmental factors in genetically susceptible population, through activation of both cellmediated and humoral immune mechanisms [3,5-7]. After ingestion of dietary sources of gluten (wheat, barley and rye), gluten peptides, modified deamidated by tissue transglutaminases expressed in the lamina propria of the small intestines, are presented by professional antigen presenting cells to gluten-specific CD4 T cells in lamina propria of the intestinal cells and oral mucosa, in the context of class II HLA molecules (DQ2 and 8). Gliadinreactive $\mathrm{T}$ cells in turn likely express interferon gamma (IFN $\gamma$ ), a T helper type 1 cytokine, which in turn activates metalloproteinases, resulting in some manifestations of the disease. It is also likely that IFN $\gamma$ enhances the production of TNF $\alpha$ which may play a major role in recruitment of lymphocytes and mucosal damage [8]. Possible sequence of events and the point of action of Etanercept are shown in cartoon format in (Figure 3).

Of relevance to the patient discussed in this report, Recurrent Aphthous Ulcers (RAU) have been reported in patients with celiac disease, with variable frequencies [9-11]. Some studies have shown no higher frequency of RAU in CD compared to controls while others have demonstrated more frequent occurrence. Cell mediated immunity and/or formation of immune complexes may play a part in RAU development in patients with CD, though the actual mechanisms are unclear. Studies from peripheral blood in otherwise healthy patients with RAU, showed multiple immune system abnormalities. These abnormalities included: depressed or reversed CD4:CD8 cell ratio (especially in patients demonstrating severe aphthous stomatitis), increased $\gamma \delta$ receptor-positive T cells in patients with active RAU compared to controls, and increased TNF $\alpha$ production [12]. In one study, patients with RAU had elevated salivary levels of TNF $\alpha$ compared to controls [13]. Increased numbers of $\gamma \delta+$ cells suggest an antibody-dependent cell-mediated cytotoxicity in RAU pathogenesis. These specific $\mathrm{T}$ cells probably produce TNF- $\alpha$, a major mediator responsible for the initiation of the inflammatory response through its effects on endothelial cell adhesion and neutrophil chemotaxis. Other inflammatory changes found in RAU lesions include elevated IL-2 and IL-6, potentially due to local tissue trauma. IL-2 can activate natural killer (NK) cells. Increased activity of these cells has been seen in active lesions, which also seems to diminish during remission. These inflammatory mediators may also have been responsible for the nonspecific symptoms suffered by the patient.

Table 3 Systemic medications which have been used for treatment of RAU

\begin{tabular}{|c|c|c|c|}
\hline Medication & Number of patients & Results/outcome & Reference \\
\hline \multirow[t]{3}{*}{ Pentoxifylline 400 mg TID } & 26 people & $\downarrow$ ulcer size & [14] \\
\hline & 14 patients & $\downarrow$ ulcers number & \\
\hline & 12 control & & \\
\hline \multirow[t]{2}{*}{ Doxycyline 20 mg BID } & 50 patients & $\uparrow$ remission & [15] \\
\hline & & $\downarrow$ pain & \\
\hline \multirow[t]{2}{*}{ Zinc sulfate 150 mg BID } & 45 patients & $\downarrow$ ulcer size & {$[16]$} \\
\hline & & $\downarrow$ symptoms & \\
\hline \multirow[t]{2}{*}{ Cholchicine (1-2) mg BID } & 169 patients & $\downarrow$ ulcer number & {$[17]$} \\
\hline & & $\downarrow$ disease duration & \\
\hline \multirow[t]{3}{*}{ Clofazimine $100 \mathrm{mg}$ QD For 1 month } & 23 patients & $\downarrow$ ulcers number & [18] \\
\hline & & $\downarrow$ disease duration & \\
\hline & & $\ln 44 \%$ & \\
\hline \multirow[t]{2}{*}{ Prednisone up to $25 \mathrm{mg}$} & 60 patients & $\downarrow$ ulcers number & [19] \\
\hline & & Faster healing & \\
\hline \multirow[t]{2}{*}{ Montelukast $10 \mathrm{mg}$ QD } & 60 patients & $\downarrow$ ulcers number & [20] \\
\hline & & Faster healing & \\
\hline \multirow[t]{2}{*}{ Thalidomide $50 \mathrm{mg}$ QD $200 \mathrm{mg}$ QD for HIV patients } & 20 HIV patients & Induce remission & [21] \\
\hline & & In HIV patients & \\
\hline Chlorambucil 0.1 mg/kg & Single case report & Remission & [22] \\
\hline Infliximab 5 mg/kg QD & Single case report & Remission & {$[23]$} \\
\hline Etanercept 25 mg BiWeekly & 40 patients & $\downarrow$ ulcers number & [24] \\
\hline Levamisole & 9 patients & $\downarrow$ ulcers number & {$[25]$} \\
\hline
\end{tabular}




\section{Response of aphthous stomatitis to diet and biological response modifiers}

Based on the immunological changes observed in RAU, biological response modifiers have been attempted by various physicians and researchers in an attempt to ameliorate or induce remission in severe disease. Systemic medications reported in the literature include pentoxifylline [14], doxycyline [15], Zinc Sulfate [16], Colchicine [17], clofazimine [18], prednisone [19], montelukast sodium [19], sulfones [20], thalidomide [21], methotrexate [22], cyclosporin, chlorambucil [23], infliximab [24], etanercept [25], interferon $\alpha$ [26], azathioprine [25] and levamisole [27] (Table 3).

Recent advances in understanding of molecular inflammatory mechanisms have led to new treatments for inflammatory disease- including tumour necrosis factor-alpha antagonists, infliximab, etanercept and adalimumab and the T-cell modulator modifiers efalizumab and alefacept [28]. Since recent studies have demonstrated a role for the newer TNF $\alpha$ inhibitors in RAS [29-31], this intervention was initiated in the patient, after informed consent.

In small case clusters or isolated reports, inhibition of TNFa has been shown to alleviate aphthous stomatitis. In one study, Infliximab, a chimeric anti-TNF $\alpha$ antibody, administered intravenously was quite effective in managing recurrent or refractory oral and genital ulcers, with no evidence of recurrence [24]. In another study, Etanercept, a fusion protein of the TNF- $\alpha$ receptor and the Fc portion of human IgG1, had a favorable effect on RAS of the oral cavity. In one review, sixteen patients underwent treatment for refractory or severe aphthous ulcers with tumor necrosis factor alpha antagonists, between 1995 and 2010 [32]. Of the drugs used, infliximab, etanercept and adalimumab appeared to improve outcomes [32]. Sanchez-Cano et al., also reported improved outcomes with adalimumab in a patients with severe aphthous ulcers [33]. The role of cytokines such as TNFo in severe aphthous stomatitis, especially in underlying disorders such as CD needs to be clarified.

Approved uses for etanercept include treatment of rheumatoid arthritis, juvenile rheumatoid arthritis, psoriatic arthritis, plaque psoriasis and ankylosing spondylitis. Recently this drug has also been utilized to treat complications in patients with HIV infection [34]. Off-label use has extended to include Behcet's disease, recurrent aphthous stomatitis, pemphigoid and lichen planus [29]. A study done by Pepple K. et al., showed that etanercept was used for treatment of Alzheimer disease with small significant improvement [35]. Another study done by Zalevsky et al., showed that the use of etanercept in HIV/AIDS does not increase morbidity or mortality; in contrast it may improve associated aphthous stomatitis, fatigue and dementia [36]. As with any other immunosuppressant, etanercept increases the risk of infections, lupus, systemic sclerosis and congestive heart failure. Etanercept may also increase risk of lymphoma, central nervous system disease such as multiple sclerosis, vasculitis and autoimmune hepatitis but in clinical trials appears to have a favorable risk-benefit ratio [37-39]. In the patient mentioned in this report, dramatic improvement in mucosal disease as well as in the systemic complications of fatigue an arthralgia was convincing enough to allow her to stay on etanercept, though the long term safety and efficacy are unknown and need to be evaluated before firm recommendations on such use could be recommended.

\section{Conclusion}

This patient had severe aphthous stomatitis complicating $\mathrm{CD}$, impairing swallowing, chewing and speaking. This led to weight loss, psychosocial issues as well as inability to perform her work. A variety of topical and systemic medications used resulted in either no improvement or only partial alleviation of her symptoms. The use of etanercept resulted in remission of aphthous stomatitis and considerable improvement of quality of life. The use of newer biological for selected and severe manifestations of $\mathrm{CD}$ may lead to improved morbidity in these patients, but more studies are indicated.

\section{Competing interests}

The authors declare that they have no competing interests.

\section{Authors' contributions}

$\mathrm{AH}$ and HP carried out conception and design of the case report, $\mathrm{AH}, \mathrm{J}$ and GY carried out literature review, AH, HP, JL, GY and GK carried out drafting the case report and final approval of the version to be published, all authors read and approved the final manuscript.

\section{Author details}

${ }^{1}$ The Department of Internal Medicine, East Tennessee State University, Johnson City, TN, USA. '2Division of Allergy, Asthma and Immunology, East Tennessee State University, PO Box 70622, Johnson City, TN, USA. ${ }^{3}$ James H. Quillen VA Medical Center, East Tennessee State University, Johnson City, TN, USA. ${ }^{4}$ Department of Pathology, Quillen College of Medicine, East Tennessee State University, Johnson City, TN, USA. ${ }^{5}$ Department of Medicine, Quillen College of Medicine, Johnson City, TN 37614-0622, USA.

Received: 2 January 2013 Accepted: 13 December 2013

Published: 24 December 2013

\section{References}

1. Gujral N, Freeman HJ, Thomson AB: Celiac disease: prevalence, diagnosis, pathogenesis and treatment. World J Gastroenterol 2012, 18(42):6036-6059.

2. Rashid M, Zarkadas M, Anca A, Limeback H: Oral manifestations of celiac disease: a clinical guide for dentists. J Mich Dent Assoc 2011, 93(10):42-46.

3. Kagnoff MF: Celiac disease. A gastrointestinal disease with environmental, genetic, and immunologic components. Gastroenterol Clin North Am 1992, 21(2):405-425.

4. Schuppan D: Current concepts of celiac disease pathogenesis. Gastroenterology 2000, 119(1):234-242.

5. Kupfer SS, Jabri B: Pathophysiology of celiac disease. Gastrointest EndosC Clin N Am 2012, 22(4):639-660.

6. McCabe MA, Toughill EH, Parkhill AM, Bossett MS, Jevic MS, Nye ML: Celiac disease: a medical puzzle. Am J Nurs 2012, 112(10):34-44.

7. Westerberg DP, Gill JM, Dave B, DiPrinzio MJ, Quisel A, Foy A: New strategies for diagnosis and management of celiac disease. J Am Osteopath Assoc 2006, 106(3):145-151. 
8. Medina M, De PG, Ribes-Koninckx C, Calabuig M, Sanz Y: Bifidobacterium strains suppress in vitro the pro-inflammatory milieu triggered by the large intestinal microbiota of coeliac patients. J Inflamm (Lond) 2008, 5:19.

9. Bucci P, Carile F, Sangianantoni A, D'Angio F, Santarelli A, Lo ML: Oral aphthous ulcers and dental enamel defects in children with coeliac disease. Acta Paediatr 2006, 95(2):203-207.

10. Ferguson MM, Wray D, Carmichael HA, Russell RI, Lee FD: Coeliac disease associated with recurrent aphthae. Gut 1980, 21(3):223-226.

11. Ferguson R, Basu MJ, Asquith P, Cooke WT: Proceedings: recurrent aphthous ulceration and its association with coeliac disease. Gut 1975, 16(5):393.

12. MacPhail L: Topical and systemic therapy for recurrent aphthous stomatitis. Semin Cutan Med Surg 1997, 16(4):301-307.

13. Eguia-del VA, Martinez-Conde-Llamosas R, Lopez-Vicente J, Uribarri-Etxebarria A, Aguirre-Urizar JM: Salivary levels of Tumour Necrosis Factor-alpha in patients with recurrent aphthous stomatitis. Med Oral Patol Oral Cir Bucal 2011, 16(1):e33-e36.

14. Thornhill MH, Baccaglini $\mathrm{L}$, Theaker $\mathrm{E}$, Pemberton MN: A randomized, double-blind, placebo-controlled trial of pentoxifylline for the treatment of recurrent aphthous stomatitis. Arch Dermatol 2007, 143(4):463-470.

15. Preshaw PM, Grainger $P$, Bradshaw $M H$, Mohammad AR, Powala $C V$, Nolan A: Subantimicrobial dose doxycycline in the treatment of recurrent oral aphthous ulceration: a pilot study. J Oral Pathol Med 2007, 36(4):236-240.

16. Sharquie KE, Najim RA, Al-Hayani RK, Al-Nuaimy AA, Maroof DM: The therapeutic and prophylactic role of oral zinc sulfate in management of recurrent aphthous stomatitis (ras) in comparison with dapsone. Saudi Med J 2008, 29(5):734-738.

17. Davatchi F, Sadeghi AB, Tehrani BA, Shahram F, Nadji A, Shams H, Chams-Davatchi C: Colchicine versus placebo in Behcet's disease: randomized, double-blind, controlled crossover trial. Mod Rheumatol 2009, 19(5):542-549.

18. de Abreu MA, Hirata CH, Pimentel DR, Weckx LL: Treatment of recurrent aphthous stomatitis with clofazimine. Oral Surg Oral Med Oral Pathol Oral Radiol Endod 2009, 108(5):714-721.

19. Femiano F, Buonaiuto C, Gombos F, Lanza A, Cirillo N: Pilot study on recurrent aphthous stomatitis (RAS): a randomized placebo-controlled trial for the comparative therapeutic effects of systemic prednisone and systemic montelukast in subjects unresponsive to topical therapy. Oral Surg Oral Med Oral Pathol Oral Radiol Endod 2010, 109(3):402-407.

20. Lynde CB, Bruce AJ, Rogers RS III: Successful treatment of complex aphthosis with colchicine and dapsone. Arch Dermatol 2009, 145(3):273-276.

21. Paterson DL, Georghiou PR, Allworth AM, Kemp RJ: Thalidomide as treatment of refractory aphthous ulceration related to human immunodeficiency virus infection. Clin Infect Dis 1995, 20(2):250-254.

22. Evereklioglu C: Current concepts in the etiology and treatment of Behcet disease. Surv Ophthalmol 2005, 50(4):297-350.

23. Zouboulis CC: Extended venous thrombosis in Adamantiades-Behcet's disease. Eur J Dermatol 2004, 14(4):268-271.

24. Haugeberg G, Velken $M$, Johnsen V: Successful treatment of genital ulcers with infliximab in Behcet's disease. Ann Rheum Dis 2004, 63(6):744-745.

25. Melikoglu M, Fresko I, Mat C, Ozyazgan Y, Gogus F, Yurdakul S, Hamuryudan V, Yazici H: Short-term trial of etanercept in Behcet's disease: a double blind, placebo controlled study. J Rheumatol 2005, 32(1):98-105.

26. Zouboulis CC, Orfanos CE: Treatment of Adamantiades-Behcet disease with systemic interferon alfa. Arch Dermatol 1998, 134(8):1010-1016.

27. Jurge S, Kuffer R, Scully C, Porter SR: Mucosal disease series. Number VI. Recurrent aphthous stomatitis. Oral Dis 2006, 12(1):1-21.

28. O'Neill ID: Off-label use of biologicals in the management of inflammatory oral mucosal disease. J Oral Pathol Med 2008, 37(10):575-581.

29. Nowak M, Dziechciarz P, Dwilewicz-Trojaczek J: The frequency of coeliac disease occurrence in patients with recurrent aphthous stomatitis (RAS)preliminary report. Wiad Lek 2002, 55(9-10):542-546.

30. Lewkowicz N, Lewkowicz P, Dzitko K, Kur B, Tarkowski M, Kurnatowska A, Tchorzewski $\mathrm{H}$ : Dysfunction of CD4+CD25high T regulatory cells in patients with recurrent aphthous stomatitis. J Oral Pathol Med 2008, 37(8):454-461.

31. Altenburg A, Zouboulis CC: Current concepts in the treatment of recurrent aphthous stomatitis. Skin Therapy Lett 2008, 13(7):1-4.

32. O'Neill ID: Efficacy of tumour necrosis factor-alpha antagonists in aphthous ulceration: review of published individual patient data. J Eur Acad Dermatol Venereol 2012, 26(2):231-235.
33. Sanchez-Cano D, Callejas-Rubio JL, Ruiz-Villaverde R, Ortego-Centeno N: Recalcitrant, recurrent aphthous stomatitis successfully treated with adalimumab. J Eur Acad Dermato/ Venereol 2009, 23(2):206.

34. Ting PT, Koo JY: Use of etanercept in human immunodeficiency virus (HIV) and acquired immunodeficiency syndrome (AIDS) patients. Int $\mathrm{J}$ Dermatol 2006, 45(6):689-692.

35. Peppel K, Crawford D, Beutler B: A tumor necrosis factor (TNF) receptor-lgG heavy chain chimeric protein as a bivalent antagonist of TNF activity. J Exp Med 1991, 174(6):1483-1489.

36. Zalevsky J, Secher T, Ezhevsky SA, Janot L, Steed PM, O'Brien C, Eivazi A, Kung J, Nguyen DH, Doberstein SK, Erard F, Ryffel B, Szymkowski DE: Dominant-negative inhibitors of soluble TNF attenuate experimental arthritis without suppressing innate immunity to infection. J Immunol 2007, 179(3):1872-1883.

37. Mehta PA, Svahn J, Davies SM, Pang $Q$, Harris R, Ghezzi P, Lanza T, Ferretti E Barabino P, Mueller R, Dufour C: Etanercept treatment in Fanconi anaemia; combined US and Italian experience. Br J Haematol 2012, 158(6):809-811.

38. Sokumbi O, Wetter DA, Makol A, Warrington $\mathrm{KJ}$ : Vasculitis associated with tumor necrosis factor-alpha inhibitors. Mayo Clin Proc 2012, 87(8):739-745.

39. Spadaro A, Lubrano E, Ferrara N, Scarpa R: Etanercept in psoriatic arthritis. J Rheumatol Suppl 2012, 89:74-76.

doi:10.1186/1476-7961-11-6

Cite this article as: Hasan et al:: Remission of severe aphthous stomatitis of celiac disease with etanercept. Clinical and Molecular Allergy 2013 11:6.

\section{Submit your next manuscript to BioMed Central and take full advantage of:}

- Convenient online submission

- Thorough peer review

- No space constraints or color figure charges

- Immediate publication on acceptance

- Inclusion in PubMed, CAS, Scopus and Google Scholar

- Research which is freely available for redistribution

Submit your manuscript at www.biomedcentral.com/submit
C) Biomed Central 